\title{
Designing organizational excellence model for cellulose industry of Iran
}

\author{
Seyed Abbas Kazemi ${ }^{a}$, Jamshid Salehi Sadaghani ${ }^{b}$, Gholam Hosein nikokar ${ }^{a}$ and Mohsen Mohammad \\ Sadeghi $^{\mathbf{a}}$
}

${ }^{a}$ Department of System Management, Imam University, Tehran, Iran

${ }^{b}$ Department of Management and Accounting, Allameh Tabatabaie University (ATU), Tehran, Iran

\begin{tabular}{|c|c|}
\hline ART ICLE I N FO & A B S T RAC T \\
\hline $\begin{array}{l}\text { Article history: } \\
\text { Received July 10, } 2011 \\
\text { Received in Revised form } \\
\text { September, 12, } 2011 \\
\text { Accepted 20 September } 2011 \\
\text { Available online } \\
\text { 25 September } 2011\end{array}$ & $\begin{array}{l}\text { Nowadays organizational excellence is regarded as the world's most effective and progressive } \\
\text { issue and many countries and organizations are attempting in the way of applying excellence. In } \\
\text { this way, they attempt to improve such models and according to culture and sociopolitical } \\
\text { conditions of each country, they attempt to design several models. The present research has } \\
\text { been conducted with principal goal of designing organizational excellence model at cellulose } \\
\text { industry of Iran. The study determines its components and aspects, priorities the aspects and }\end{array}$ \\
\hline $\begin{array}{l}\text { Keywords: } \\
\text { Organizational excellence } \\
\text { EFQM } \\
\text { TQM } \\
\text { LISREL } \\
\text { Cellulose Industry }\end{array}$ & $\begin{array}{l}\text { components and analyzes relationship among different aspects of organizational excellence } \\
\text { model at cellulose industry of Iran. The present research is an applied research with respect to } \\
\text { goal and it is a descriptive-analytical method in terms of method. Statistical population of the } \\
\text { present research covers all experts in the field of cellulose industry of Iran in which on this } \\
\text { basis, the number of statistical sample was } 207 \text { people from managers to specialists. Results of } \\
\text { research indicate that organizational excellence pattern of cellulose industry is a mixture of } \\
\text { different aspects of technical, economic, inner environment, outer environment, motivation and } \\
\text { behavioral processes. }\end{array}$ \\
\hline
\end{tabular}

\section{Introduction}

Nowadays organizations face with two factors of speed and depth for evolutions in which these they have changed business literature. If changes are more complicated, organizations may require more to knowledge of environmental factors so that they will be able to adapt themselves with environmental changes. Therefore, while planning for future, compiling strategy and adaption of organization for executing the strategy, awareness of weak and strong points and recognizing suitable context for organization are regarded as vital issues. On the other hand, quality and effectiveness are among principal concepts of management science, i.e. the issue, which may be regarded as the best index for indicating attention to customers is quality. Quality as comprehensive property is a mixture of elements such as marketing, research, development, designing, manufacturing product and offering service to customer. Therefore, improving quality may be considered as one of the principal

* Corresponding author. Tel: + 982122915269

E-mail addresses: sadeghi7310@yahoo.com (M. Mohammad Sadeghi) 
approaches for improving organizational ability for improving processes, products and services. In order to have this assumption and insight for organization, it is required to have an assessment model. Nowadays according to experience of successful companies and comment of scientists, several models are offered for self-assessment. Using this model as a framework for preparing required image not only grants required insight to management within macro scale; but also prepares map with complete details for people inside of organization to play their role on punctual and correct basis. Progressive organizations to identify successful path and improving their performance apply from effective solutions called self-assessment. The main result of self-assessment is to identify and determine strong points and context for improvement i.e. self-assessment as mirror shows the real nature of everything and consequently organization is able to observe and assess the present status and attempt for reaching a suitable status. Therefore, organization may have excellence, which attracts many factors such as quality and self-assessment in all levels of organization. Thus, quality is a starting point for organizational excellence.

Saizarbitoria et al. (2006) analyzed the influence on European companies' performance of the two most popular models for quality management (QM) practice, which are the ISO 9000 and the EFQM. In their method, they used a qualitative survey carried out in Spain using the Delphi method, based on previous research work and they analyzed the results and compared with the results of other surveys carried out previously, as well as with information gathered during several in-depth interviews of the experts that participated in their Delphi panel (Linstone, \& Turoff, 2002).

All models of organizational excellence are developed based on concept and philosophy of quality management and the primary goal of these models is to obtain comprehensive quality. Such philosophy may be true for all organizations with respect to status, size or section (Christina \& Colurcio, 2006). In this way, we have applied from several organizational excellence patterns such as EFQM, Baldridg (Hakes, 2007), Deming $(1986,2000)$ and cellulose company's prizes to reach organizational excellence's objectives. Whereas increasing level of society's health, production of cellulose industries of Iran have found good market, but unfortunately Chinese and Turkish companies threatening this market by offering different goods and eye-catching package. Despite the fact that cellulose industry has many years of experience, it cannot meet customer expectations in terms of quality of goods, innovation and present needs of market and customer expectations. Therefore, customers are more preferred to purchase high quality foreign products. As we can observe from our discussion, we need to build a suitable model for developing this industry using both national and religious believes to meet the Iranian requirements.

There are literally two different types of excellence any organization could follow, which are customer and organizational excellence. The first one is associated with fulfilling direct demands of customer like quality, price, ability of trust, ability of performance, after sale services, satisfaction, validity, fame and beauty. The second one is concerned with direct attraction of organization like growth, market share, profitability, anticipation, lifetime, working culture and validity. Oakland (2005) presented a comprehensive discussion on all aspects of organizational and customer excellence. Zilka (2009) explains excellence as any inclusive development means increasing enthusiasm for satisfying people's requirements. Organizational excellence is also defined as a set of leadership values and strategies for evolution and skill in which the key of organizational excellence is excellence leadership. Leadership depends on four principles of enjoy, hope, peace and love and its strategies are to look for vision, approach and significance through communication, trust, stability of situation and trust through respect and skills including vision, think, feel, know, act and trust and ability of communicate. Organizational excellence is in fact development and execution of leadership strategies. To obtain such excellence it is required to take care of customer and it is necessary to create obligated and innovator personnel (Sam, 2008).

In order to reach excellence, it is required to have special attention to the following items: human, process, production and customer (Tito, 2007). Another method for obtaining excellence is measuring 
performance, thus it is required to measure tangible items such as capital return rate, cost liquidity, sale and non-tangible items such as quality, customer satisfaction, security and trust (Dublin, 2009). Organizational excellence is obtained through observing five principles such as: thinking, strategic planning, and taking pattern from best excellences, guiding cooperation, public obligation and sovereignty by standards of development (Thomas, 2004).

\section{The proposed model}

\subsection{Organizational excellence in Islam}

Although organizational excellence is a new concept originated from western countries, it has many shortages in which only by having religious approach and observing Islamic principles, it is possible to find out its truthfulness. Thus, organization that does not intend to deal with aspects of human excellence is convicted to disintegration and any type of pattern without observing spiritual aspects and cleanness of soul is incomplete pattern, which is never able to completely play its role.

The organization of this paper first presents the relevant literature review, hypothesis and proposed model in section 2. Section 3 discusses details of our results and concluding remarks are given in section 4 to summarize the contribution of the paper.

\subsection{Research conceptual model}

Creating culture is to coin abstract concept for understanding real issue. Creating a concept in first step is determining factors, which form it and reflect real issue (Kiwi, 2005). Conceptual model is based on theoretical relationships between effective factors and variables on subject of research (Craciun, 2010). Designing desired pattern of the present research is the goal of designing organizational excellence model of cellulose industry, which is performed with special goal. The main factors and criteria are illustrated in Fig.1.

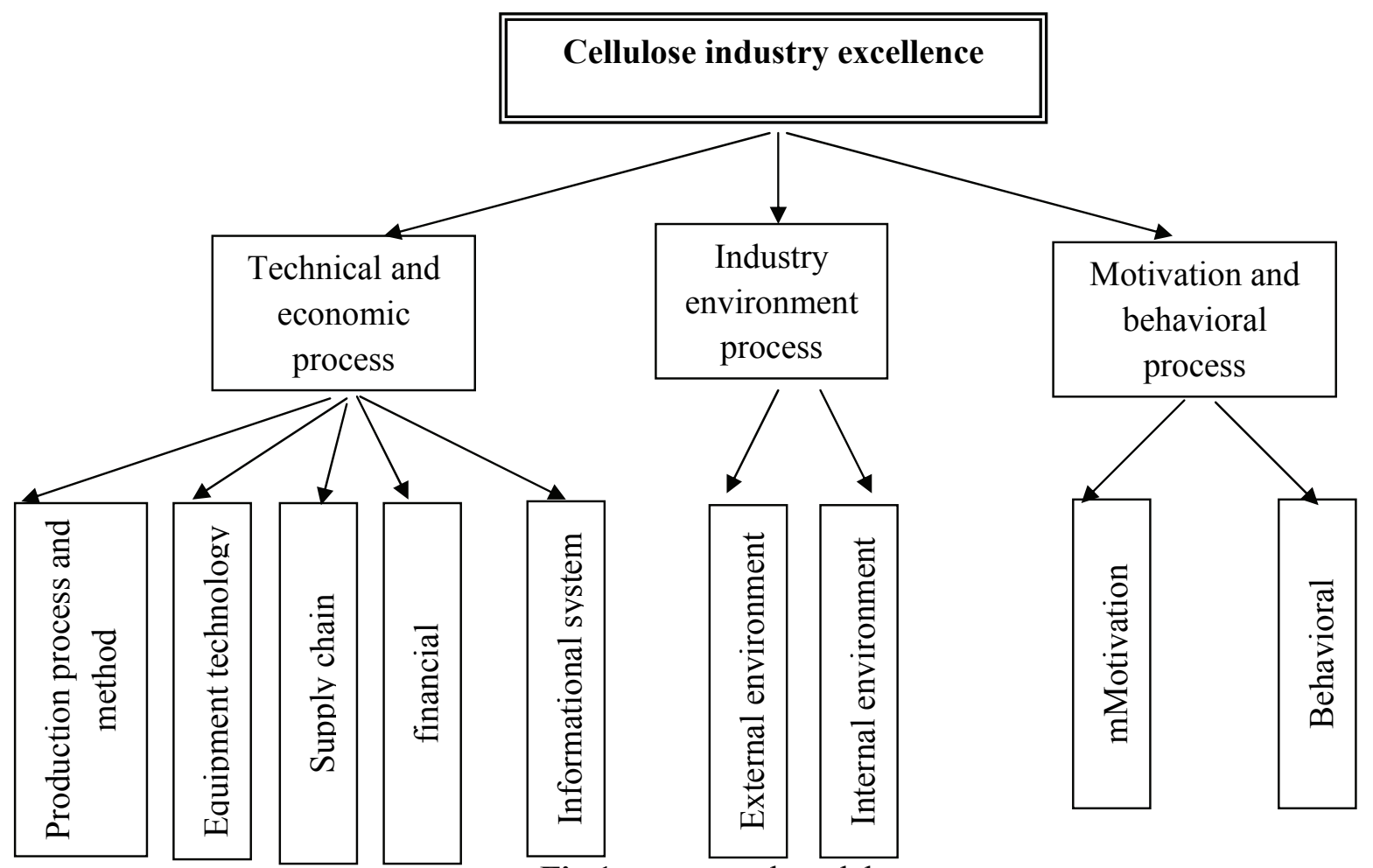

Fig.1. conceptual model 
According to studies in relation to models of organizational excellence, we have concluded that due to special condition of cellulose industry of Iran, none of them is complete and suitable model for organizational excellence of cellulose industry. In the present research, by observing research literature and benefiting strong point of approaches and different patterns, a suitable model for organizational excellence of cellulose industry of Iran by observing technical, economic, internal environment, external environment, motivation, behavioral processes and their direct and mutual effect is designed. On this basis, research hypotheses are as follows:

\subsection{Principal hypothesis of research}

The model for organizational excellence of cellulose industry of Iran is a mixture of technical, economic, internal environment, external environment, motivation, behavioral processes factors.

\subsubsection{Minor hypothesis}

1) The proposed model for organizational excellence of cellulose industry of Iran, we use various criteria such as supply chain, financial, machineries, processes and methods of production, information system management, customer orientation, research and development, innovation and continuous improvement.

2) The proposed model for organizational excellence of cellulose industry of Iran also uses management, structure, human resources, and shareholder's perspectives.

3) The proposed model for organizational excellence of cellulose industry of Iran gathers idea from economic, political, cultural and legal criteria.

4) The proposed model for organizational excellence of cellulose industry of Iran implements different criteria of training, job security, lack of discrimination, mutual respect and trust, accepting guardianship, pray, prevention from religious illegal issue, self-assessment and Islamic management behavior.

\subsection{Research method}

There proposed research of this paper is an empirical analysis based on descriptive-analytical research. Statistical populations of the present research are experts in cellulose industry of Iran and it gathers 207 people using random sampling method. Method of collecting information was questionnaire and it was used from confirmative factor analysis and Liesrel software for content validity and formal validity. In addition, in order to assess reliability of questionnaire, factors and criteria of organizational excellence of cellulose industry of Iran are incorporated. The Cronbach's Alpha for the results was 0.989 , which is highly acceptable coefficient. Therefore, assessment tool of the present research has high reliability.

\section{The results of the survey}

The results of our survey for the main hypothesis when $\mathrm{H}_{0}: \mathrm{P}=60 \%$ is summarized in Table 2 .

\section{Table 2}

Results of binominal test for main hypothesis of research

\begin{tabular}{lllll}
\hline Binominal test results & $\begin{array}{l}\text { Motivation-behavioral } \\
\text { process }\end{array}$ & $\begin{array}{l}\text { External } \\
\text { environment process }\end{array}$ & $\begin{array}{l}\text { Internal environment } \\
\text { process }\end{array}$ & $\begin{array}{l}\text { Technical } \\
\text { economic process }\end{array}$ \\
\hline Hypothesis ratio & 0.6 & 0.6 & 0.6 & 0.6 \\
Observed ratio & 0.89 & 0.85 & 0.88 & 1 \\
T & 6.34 & 6.44 & 6.21 & 6.24 \\
Sig level & 0.000 & 0.000 & 0.000 & 0.000 \\
Test result & H0(reject) & H0(reject) & H0(reject) & H0(reject) \\
Friedman Mean Rank & 3.69 & 2.22 & 2.65 & 3.27 \\
Ranking & 1 & 4 & 3 & 2 \\
\hline
\end{tabular}


Results of non-parametric binominal test reveals that the ratio of technical and economic processes is 1 , internal processes is 0.88 , external processes is 0.85 , behavioral and motivation processes is 0.89 in which there is no significant difference with the ratio of our hypothesis. Therefore, principal hypothesis of research i.e. (in model for organizational excellence of cellulose industry of Iran, it is applied from technical, economic, internal environment, external environment, motivation, behavioral processes) is confirmed. In addition according to Freedman mean rank, priority of influencing these processes is as follows: behavioral, motivation, technical, economic, internal environment and external environment processes. We have also performed similar test for our minor hypothesis and the results are summarized in Table 3.

Table 3

Results of binominal test for minor hypothesis of research

\begin{tabular}{|c|c|c|c|c|c|c|c|c|}
\hline Factor & Criteria & $\begin{array}{l}\text { Hypothesis } \\
\text { ratio }\end{array}$ & $\begin{array}{l}\text { Observed } \\
\text { ratio }\end{array}$ & $\mathrm{T}$ & Sig. & Test result & $\begin{array}{l}\text { Mean } \\
\text { Rank }\end{array}$ & Ranking \\
\hline \multirow{8}{*}{ 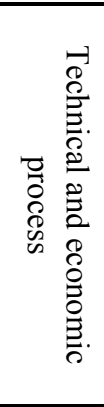 } & Supply chain & 0.6 & 0.9 & 9.93 & 0.000 & H0(reject) & 3.72 & 9 \\
\hline & Financial & 0.6 & 0.87 & 9.71 & 0.000 & $\mathrm{H} 0$ (reject) & 2.6 & 21 \\
\hline & Equipment & 0.6 & 0.79 & 11.76 & 0.000 & $\mathrm{HO}($ reject) & 3.8 & 7 \\
\hline & Production method and process & 0.6 & 0.88 & 10.52 & 0.000 & $\mathrm{H} 0$ (reject) & 2.96 & 17 \\
\hline & $\begin{array}{l}\text { Information management } \\
\text { system }\end{array}$ & 0.6 & 0.88 & 10.87 & 0.000 & $\mathrm{HO}$ (reject) & 2.87 & 18 \\
\hline & Customer orientation & 0.6 & 0.89 & 9.44 & 0.000 & $\mathrm{H} 0$ (reject) & 3.7 & 10 \\
\hline & Research and development & 0.6 & 0.89 & 11.32 & 0.000 & $\mathrm{H} 0$ (reject) & 2.29 & 23 \\
\hline & $\begin{array}{l}\text { Innovation and continuous } \\
\text { improvement }\end{array}$ & 0.6 & 0.87 & 8.72 & 0.000 & $\mathrm{H} 0$ (reject) & 3.6 & 11 \\
\hline \multirow{4}{*}{ 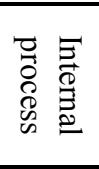 } & Management & 0.6 & 0.90 & 8.44 & 0.000 & H0(reject) & 3.2 & 14 \\
\hline & Structure & 0.6 & 0.96 & 9.86 & 0.000 & $\mathrm{H} 0$ (reject) & 2.45 & 22 \\
\hline & Human resource & 0.6 & 0.95 & 9.67 & 0.000 & $\mathrm{H} 0$ (reject) & 2.87 & 19 \\
\hline & Shareholders rights & 0.6 & 1 & 10.23 & 0.000 & $\mathrm{H} 0$ (reject) & 2.11 & 25 \\
\hline \multirow{4}{*}{ 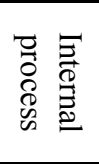 } & Economic & 0.6 & 0.97 & 8.31 & 0.000 & H0(reject) & 2.62 & 20 \\
\hline & Political & 0.6 & 0.89 & 7.67 & 0.000 & $\mathrm{H} 0$ (reject) & 2.03 & 27 \\
\hline & Cultural & 0.6 & 0.9 & 8.11 & 0.000 & $\mathrm{H} 0$ (reject) & 2.16 & 24 \\
\hline & Legal & 0.6 & 0.86 & 7.73 & 0.000 & $\mathrm{H} 0$ (reject) & 2.1 & 26 \\
\hline \multirow{10}{*}{ 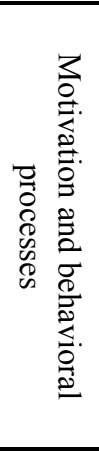 } & Training & 0.6 & 0.86 & 9.34 & 0.000 & H0(reject) & 3.25 & 12 \\
\hline & Job security & 0.6 & 0.82 & 9.04 & 0.000 & $\mathrm{H} 0$ (reject) & 3.81 & 6 \\
\hline & Lack of discrimination & 0.6 & 0.82 & 9.07 & 0.000 & $\mathrm{H} 0$ (reject) & 3.79 & 8 \\
\hline & Mutual respect and trust & 0.6 & 0.84 & 9.23 & 0.000 & $\mathrm{H} 0$ (reject) & 3.15 & 16 \\
\hline & Accepting guardianship & 0.6 & 0.76 & 9.87 & 0.000 & $\mathrm{H} 0$ (reject) & 3.99 & 1 \\
\hline & Pray & 0.6 & 0.89 & 15.7 & 0.000 & $\mathrm{H} 0$ (reject) & 3.97 & 2 \\
\hline & Bonus & 0.6 & 0.99 & 9.85 & 0.000 & $\mathrm{HO}$ (reject) & 3.88 & 5 \\
\hline & $\begin{array}{l}\text { Prevention from religious illegal } \\
\text { issues }\end{array}$ & 0.6 & 0.73 & 7.91 & 0.000 & $\mathrm{H} 0$ (reject) & 3.92 & 4 \\
\hline & Self-assessment & 0.6 & 0.8 & 8.87 & 0.000 & $\mathrm{H} 0$ (reject) & 3.22 & 13 \\
\hline & Islamic management behavior & 0.6 & 0.84 & 7.97 & 0.000 & $\mathrm{H} 0$ (reject) & 3.92 & 3 \\
\hline
\end{tabular}

The results of non-parametric binominal test reveal that the ratio for all components was higher than 0.6 and T-value was higher than 2, which means there is no significant difference with hypotheses. Therefore, minor hypotheses of research are confirmed. In addition, based on Freedman mean rank, the priority of influencing subsidiary components is as follows: accepting guardianship, pray, Islamic management behavior, prevention from religious illegal issue, bonus, job security, machineries, lack of discrimination, supply chain, customer orientation, innovation, continuous improvement, training, self-assessment, management, mutual respect and trust, method and process of production, information management system, human, economic, financial resources, structure, research and development, cultural, shareholder legal and political criteria. 


\section{Conclusion}

In this paper, we have designed an organizational excellence model for cellulose industry of Iran. There proposed study of this work has considered four factors influencing organizational excellence. The first factor includes supply chain, financial, bonus, machineries, research and development, information system management, customer orientation, research and development, innovation and continuous improvement. The second factor of research covers management, structure, human resources and shareholders. The third factor includes economic, political, cultural and legal and finally fourth includes training, job security, lack of discrimination, mutual respect and trust, accepting guardianship, pray, bonus, prevention from religious illegal issue, self-assessment, and Islamic management behavior. Priorities of influencing factors on organizational excellence of cellulose industry obtained from Freedman's test are behavioral-motivation, technical, economic, internal processes and external processes. The results of research have indicated that organizational excellence pattern of cellulose industry is a mixture of different aspects of technical, economic, inner environment, outer environment, motivation and behavioral processes.

\section{Acknowledgement}

The authors would like to thank the anonymous referees for their detailed contribution on earlier version of this work.

\section{References}

Christina, M., \& Colurcio, M. (2006). The evolving path of T.Q.M: Towards business excellence and stakeholder value. International Journal of Quality and Reliability management, 23(5), 469-489.

Cronbach, L. J. (1951). Coefficient alpha and the internal structure of tests. Psychometrika, 16(3), 297-334.

Deming, W. E. (1986). Out of the Crisis. MIT Press. ISBN 0-911379-01-0.

Deming, W. E. (2000). The New Economics for Industry, Government, Education (2nd ed.). MIT Press. ISBN 0-262-54116-5.

Dublin. T. L. (2009). Achieving Organizational Excellence through the performance measurement. Journal of System Research and Markets, Guinness Centre, Ireland.

Hakes, C. (2007). The EFQM Excellence Model: For Assessing Organizational Performance - A Management Guide. Van Haren Publishing, ISBN 978-90-8753-027-3.

Linstone, A., \& Turoff, M. (2002). The Delphi Method: Technique and Applications. e-book, available at: www.is.njit.edu/pubs/delphibook/.

Ockland, J.S. (2005). Total organizational excellence, Industrial press, New York.

Sam, A. (2008). Investigating the impact of Organizational Excellence and leadership on business performance: An exploratory study of Turkish firm, Advanced Management Journal, 12(5), 125138.

Saizarbitoria, I. H., Landín, G. A., \& Fa, M. C. (2006). The impact of quality management in European companies' performance: The case of the Spanish companies. European Business Review, 18(2), 114-131.

TiTo, C. A. (2007). A history and Review of the European quality award model. The TQM magazine, 19(2), 112-123.

Thomas, R. S. (2004).The essentials of Organizational Excellence, Industrial Press, New York.

Zilka, C. (2009). Business Restructuring: An Action Template for Reducing Cost and Growing Profit.1st ed. Wiley. 